\title{
ANALISIS AWAL RANCANGAN SISTEM PGNAA MENGGUNAKAN SUMBER NEUTRON DARI BEAMPORT REAKTOR KARTINI
}

\author{
Edi Trijono Budisantoso, Syarip \\ Pusat Sains \& Teknologi Akselerator \\ JL. Babarsari Kotak Pos:6101 Jogjakarta 55281 \\ E-mail: edi-t@batan.go.id \\ Diterima: 01-06-2016 \\ Diterima dalam bentuk revisi: 22-02-2017 \\ Disetujui: 23-02-2017
}

\begin{abstract}
ABSTRAK
ANALISIS AWAL RANCANGAN SISTEM PGNAA MENGGUNAKAN SUMBER NEUTRON DARI BEAMPORT REAKTOR KARTINI. Telah dilakukan analisis awal rancangan sistem PGNAA menggunakan salah satu beamport reaktor Kartini sebagai sumber neutron. Analisis awal ini meliputi penentuan moderator dan kolimator neutron analisis berkas neutron sejajar, dan beam shutter serta beam stopper. Perhitungan sifat neutronik dilakukan untuk memilih bahan material yang memenuhi syarat fungsi sebagai sub-komponen PGNAA dan menentukan ukuran geometrinya. Dari hasil perhitungan diperoleh data bahan yang baik untuk moderator yaitu grafit, bahan kolimator adalah aluminium, bahan beam shutter dan beam stopper adalah komposit boraks-parafin. Panjang moderator $90 \mathrm{~cm}$, panjang kolimator $173 \mathrm{~cm}$ dengan tetapan kolimasi $\mathrm{D} / \mathrm{L}=0,015$, tebal beam shutter dan beam stopper masing-masing 22 $\mathrm{cm}$ dan $30 \mathrm{~cm}$. Dipasang perisai gamma dan perisai neutron untuk menutup berkas neutron keluar dari sela dinding dalam beamport dan dinding luar kolimator. Bahan perisai tersebut dibuat dari komposit boraks parafin $25 \%$ berat dan timbal yang masing-masing panjangnya 50 $\mathrm{cm}$ dan $30 \mathrm{~cm}$. Hasil analisis menunjukkan bahwa dari fluks neutron awal pada beamport bagian dalam $1,5.10^{12} \mathrm{n} / \mathrm{cm}^{2} \mathrm{~s}$ dapat dihasilkan fluks neutron termal di ruang sampel PGNAA $1,76.10^{8} \mathrm{n} / \mathrm{cm}^{2} \mathrm{~s}$ dengan arus neutron termal $9,29.10^{8} \mathrm{n} / \mathrm{s}$. Nilai fluks neutron termal tersebut memenuhi persyaratan untuk suatu sistem PGNAA yaitu berada pada orde $10^{6} \mathrm{~s} / \mathrm{d} 10^{8} \mathrm{n} / \mathrm{cm}^{2} \mathrm{~s}$.
\end{abstract}

Kata kunci: PGNAA, analisis awal, beamport, fluks neutron, reaktor, Kartini

\begin{abstract}
PRELIMINARY ANALYSIS OF PGNAA DESIGN USING NEUTRON SOURCE FROM BEAMPORT OF KARTINI REACTOR. A preliminary design analysis of PGNAA system using one of the Kartini reactor beamports as a neutron source have been carried out. This preliminary analysis includes determining neutron moderator and collimator, the analysis of parallel neutron, beam shutter and beam stopper. Calculation of neutronic properties of materials was done to choose the material that meet the functional requirements of PGNAA and to determine the geometry size. Based on the calculational results obtained that good material for moderator is graphite, aluminum as beam collimator, and beam shutter or stopper is made from borax-paraffin composite. The moderator length is $90 \mathrm{~cm}$ and collimator length is $173 \mathrm{~cm}$ with collimation constant $D / L=0,015$. Beam shutter and beam stopper thickness are $22 \mathrm{~cm}$ and $30 \mathrm{~cm}$ respectively. Gamma and neutron shield are added surrounding beam colimator to shield the radiation out from the pitch between collimator and beamport wall. The shield material made from composite of parrafin $25 \mathrm{w} \%$ borax, and lead with the length of $50 \mathrm{~cm}$ and $30 \mathrm{~cm}$ respectively. The analysis result shows that from the neutron flux of $1,5.10^{12} \mathrm{n} / \mathrm{cm}^{2} \mathrm{~s}$ at the inner side of beamport, can be generated thermal neutron flux at the PGNAA sample chamber of $1,76.10^{8} \mathrm{n} / \mathrm{cm}^{2} \mathrm{~s}$ with the thermal neutron current of $9,29.10^{8} \mathrm{n} / \mathrm{s}$. This thermal neutron flux meet the requirement for a PGNAA system i.e. in the order of $10^{6}$ to $10^{8} \mathrm{n} / \mathrm{cm}^{2} \mathrm{~s}$.
\end{abstract}

Keywords: PGNAA, beamport, neutron flux, Kartini, reactor 


\section{PENDAhULUAN}

Prompt Gamma Neutron Activation Analysis (PGNAA) adalah suatu metode analisis unsur dalam suatu bahan yang dapat dilakukan secara cepat. Metode ini menggunakan teknik aktivasi target dengan neutron termal yang secara simultan dilakukan analisis spektrum gamma serentak yang dipancarkan oleh inti target pada keadaan teraktivasi. Radiasi gamma serentak dipancarkan inti target yang menangkap neutron dan mengalami eksitasi energi. Radiasi gamma tersebut mencirikan spesifik atom yang memancarkannya. Dengan menggunakan instrumentasi pencacahan gamma resolusi dan sensitivitas tinggi serta dilakukan secara online dapat diperoleh hasil analisis komposisi unsur dalam sampel secara cepat.

Menurut IAEA (1) teknik PGNAA pada umumnya banyak diterapkan untuk analisis unsur unsur organik $\mathrm{H}, \mathrm{C}, \mathrm{N}, \mathrm{O}, \mathrm{F}, \mathrm{P}, \mathrm{S}, \mathrm{Cl}$ dan unsur yang memiliki tampang lintang serapan neutron tinggi seperti $\mathrm{B}, \mathrm{Cd}, \mathrm{Sm}$, As dan Gd yang kebanyakan meluruh sangat cepat sehingga tidak bisa diukur dengan metode analisis aktivasi neutron biasa atau NAA. Qian Zhu (2) menuliskan bahwa metode PGNAA banyak diterapkan dalam sistem pengendalian dan pengolahan batubara yang membutuhkan analisis kualitas batubara secara on-line, tulisan Henry Kurth (3) dan Darrel Leetham (4) terkait PGNAA pada pertambangan fospat dan industri semen. Sementara itu Muhammad Saleem (5), Massimo R (6), dan A.A. Naqvi (7) membuktikan PGNAA cukup akurat untuk uji kualitas keramik dan material terkait, serta untuk analisis sampel lingkungan, bahkan untuk mendeteksi ranjau darat seperti yang ditulis oleh $\mathrm{D}$. L. Chichester (8), Dariush Rezai (9).

Komponen penyusun sistem PGNAA terdiri dari sumber neutron, moderator, kolimator, perisai neutron, perisai gamma dan peralatan pencacahan spektrometri gamma. Kinerja PGNAA dikatakan baik apabila sistem tersebut dapat menghasilkan spektrometri gamma serentak dengan noise rendah, parameter ini menjadi salah satu parameter yang dipertimbangkan di dalam perhitungan dan analisis rancangan., Adapun fluks neutron termal yang harus dipenuhi dan layak untuk PGNAA sesuai dengan rujukan IAEA (1), Manuel L. et. al. (13), Zizhu Zhang et.al. (17), dan Robinson J.A. et.al. (18), adalah berkisar pada orde $10^{6} \mathrm{~s} / \mathrm{d} 10^{8} \mathrm{n} / \mathrm{cm}^{2} \mathrm{~s}$. Untuk mendapatkan PGNAA dengan kualifikasi tersebut di atas dibutuhkan perencanaan konstruksi geometri dan pemilihan bahan yang diperhitungkan dengan memperhatikan sifat interaksi neutron dengan materi dan spektrum energi neutron yang dikendalikannya. Pada prinsipnya neutron berenergi tinggi menghasilkan sifat interaksi dengan atom medium lebih kompleks daripada neutron energi rendah sehingga dalam merencanakan sistem PGNAA perlu mempertimbangkan proses moderasi untuk membuat spektrum energi neutron berubah menjadi termal sebelum dimanfaatkan dalam sistem PGNAA.

Pada perencanaan model PGNAA ini diperhitungkan bahan dan ukuran yang dapat memoderasi neutron dari sumbernya sehingga neutron berubah menjadi termal 
kemudian dikolimasi untuk menjadi neutron termal dengan berkas sejajar yang diarahkan menuju target analisis dalam ruang pencacahan PGNAA. Perhitungan sifat moderasi dilakukan berdasar pada sifat tampang lintang makroskopis bahan terhadap neutron. Perhitungan kualitas kolimator didasarkan pada perbandingan antara diameter dengan panjang kolimator. Makin besar nilai perbandingannya akan menghasilkan berkas neutron yang mendekati sejajar sedangkan hamburan dan serapan oleh udara di dalam kolimator dibuat rendah dengan memvakumkan medium kolimator.

\section{TEORI}

PGNAA adalah sebuah sistem analisis spektrum gamma yang berasal dari inti yang mengalami eksitasi energi karena menangkap neutron. Energi gamma yang dipancarkan adalah spesifik atom yang memancarkannya. Atom tersebut merupakan bagian dari elemen-elemen yang menyusun komposit target analisis. Dengan analisis spektrum gamma yang dipancarkannya dapat diketahui kandungan elemen-elemen dalam sebuah target iradiasi beserta konsentrasinya. Proses interaksi inti dalam target PGNAA dapat dilukiskan seperti pada Gambar 1

Sistem PGNAA membutuhkan berkas neutron sejajar yang menyinari target secara terus menerus sehingga unsur-unsur pokok dalam target dapat menangkap neutron dan memancarkan radiasi gamma serentak yang kemudian dideteksi oleh spektrometer gamma. Sebagai indikator analisis adalah energi dan intensitas sinar gamma yang masing-masing menunjukkan jenis elemen konsentrasi elemen pemancarnya. Radiasi gamma serentak dapat langsung terdeteksi melalui analisis spektrum dan secara cepat diketahui komposit unsur-unsur dalam target ketika target dalam paparan radiasi neutron. Radiasi gamma peluruhan tidak mengganggu analisis karena intensitasnya jauh lebih kecil dari gamma serentak. Sistem pgnaa yang dapat mendukung proses ini membutuhkan kriteria pengendalian radiasi neutron yang ketat sehingga tidak ada neutron yang bocor keluar sistem PGNAA dan menimbulkan gangguan pada analisis spektrum gamma yang terjadi. Kriteria pengendalian neutron dapat dideskripsikan melalui proses moderasi, kolimasi, dan perisai radiasi.

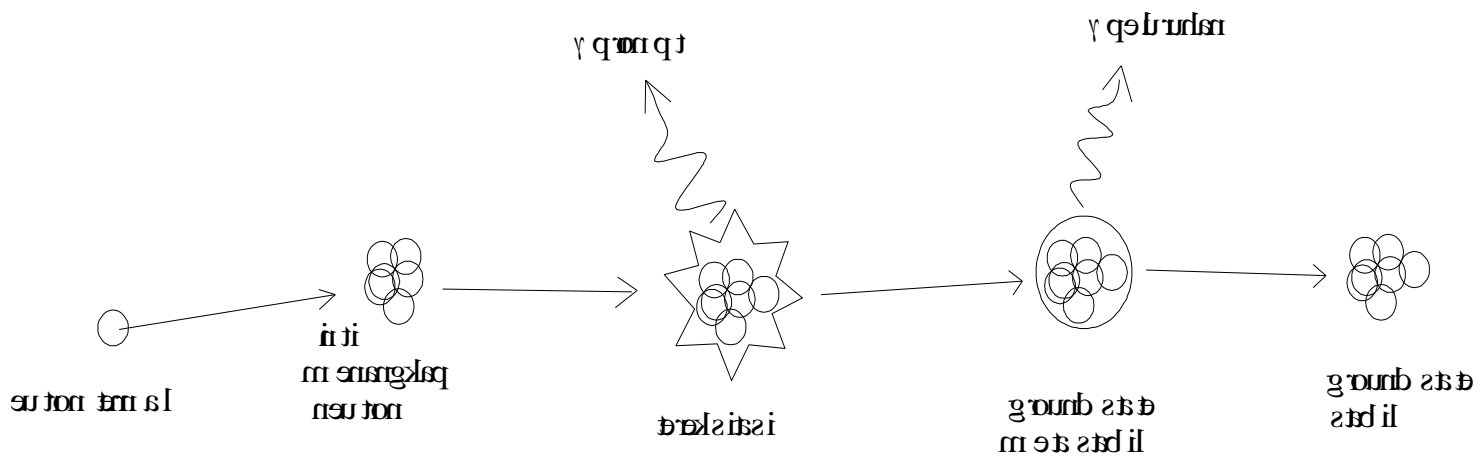

Gambar 1. Proses kebolehjadian radiasi gamma dalam target PGNAA 
Apabila neutron berenergi tinggi bertumbukan dengan inti hidrogen atau atom ringan lainnya akan berakibat neutron kehilangan sebagian besar energi karena berpindah ke inti yang ditumbuknya. Fenomena ini menjadi dasar proses moderasi neutron. Moderator yang baik, mempunyai tampang serapan neutron kecil tetapi tampang hamburan neutron besar dan mempunyai nomor massa kecil. Apabila medium berupa komposit maka tampang lintang makroskopis ditetapkan berdasarkan pada rapat atom elemen molekul medium yang diperhitungkan Glasstone S (12) sbb.:

$$
N_{i}=\frac{\rho}{m o l} N_{a} n_{i}
$$

di mana $\rho$ rapat massa komposit, mol berat molekul komposit, $\mathrm{N}_{\mathrm{a}}$ bilangan Avogadro, $\mathrm{n}_{\mathrm{i}}$ jumlah atom I dalam molekul komposit, dan $\mathrm{Ni}$ rapat atom unsur i dalam komposit.

Tampang lintang makroskopis molekul komposit diperhitungkan sebagai jumlah tampang lintang makroskopis masing-masing elemen yang terdapat dalam komposit dan dituliskan sebagai:

$$
\begin{aligned}
& \Sigma_{a}=\sum_{1}^{j} N_{i} \sigma_{a i} \quad \Sigma_{s}=\sum_{1}^{j} N_{i} \sigma_{s i} \\
\Sigma_{t}= & \sum_{1}^{j} N_{i} \sigma_{t i}
\end{aligned}
$$

di mana $\Sigma_{\mathrm{a}}, \Sigma_{\mathrm{s}}, \Sigma_{\mathrm{t}}$, adalah tampang lintang makroskopik molekul komposit, $\sigma_{\mathrm{ai}}, \sigma_{\mathrm{si}}, \sigma_{\mathrm{ti}}$, adalah tampang lintang mikroskopik atom unsur $\mathrm{i}$, dan $\mathrm{j}$ adalah jumlah ragam unsur dalam komposit.
Proses moderasi neutron dapat diamati dengan memperhitungkan parameter tumbukan berkas neutron dalam medium moderator meliputi proses penurunan energi logaritmik, jarak bebas rerata, jumlah tumbukan, efisiensi dan daya moderasi. Penurunan energi logartmik ( $\zeta)$ dari setiap neutron yang menumbuk atom medium, dapat dituliskan sbb. Glasstone S (12):

$$
\xi=\frac{4 A}{(1+A)^{2}}
$$

Jarak bebas rerata neutron diantara dua tumbukan yang dialaminya dapat dituliskan sebagai $\lambda_{i}=\frac{1}{\sum_{t}}$. Jumlah tumbukan yang dialami neutron cepat $(E=1$ $\mathrm{MeV})$ untuk menjadi termal $(E=0,025 \mathrm{eV})$, digunakan untuk membandingkan jumlah tumbukan neutron dalam medium komposit sebelum menjadi termal, dituliskan sebagai:

$$
C=\frac{\ln \frac{E_{1}}{E_{2}}}{\xi}
$$

Efisiensi penurunan energi logaritmik neutron per satuan panjang jejak selama proses moderasi, efisiensi moderasi digunakan korelasi $\xi \frac{\Sigma_{S}}{\Sigma_{a}}$, sedangkan daya moderasi yaitu penurunan energi logaritmik neutron per satuan panjang jejak selama proses moderasi dalam medium digunakan korelasi Glasstone S (12): 


$$
\xi \Sigma_{S}=\frac{\rho N_{a}}{M}\left(n_{1} \sigma_{s 1} \xi_{1}+n_{2} \sigma_{s 2} \xi_{2}+\ldots \ldots . . .\right)(5) \quad \frac{I_{m}}{I_{0}}=\frac{A \exp \left(\Sigma_{a} L_{m}\right)}{4 \pi\left(L_{m}\right)^{2}}
$$

Apabila berkas neutron sejajar menembus medium tebal $\mathrm{x}$, perubahan intensitas berkas neutron $I_{0}$ setelah menembus medium tebal $x \mathrm{~cm}$ mempunyai kebolehjadian menjadi $I_{x}$ yang diperhitungkan mengikuti fungsi exponensial yaitu:

$$
I_{x}=I_{0} e^{-N \sigma_{t} x}=I_{0} e^{-\Sigma_{t} x}
$$

$I_{x} / I_{0}$ adalah nilai kebolehjadian neutron yang Iolos interaksi dengan atom medium. Faktor perbandingan $\mathrm{I}_{x} / \mathrm{I}_{0}$ yang dituliskan sebagai $e^{-\Sigma_{t} x}$ dapat dinyatakan sebagai faktor kebolehjadian neutron tidak mengalami tumbukan dengan inti atom selama menembus medium tebal $\mathrm{x} \mathrm{cm}$. Demikian juga apabila yang digunakan adalah $\Sigma_{s}$ atau $\Sigma_{a}$ maka faktor yang diperoleh dalam perhitungan adalah kebolehjadian neutron lolos dari hamburan atau serapan inti medium yang dilewatinya.

Perhitungan arus neutron dalam PGNAA dilakukan dengan asumsi sumber neutron sebagai sumber titik yang memancar ke segala arah secara isotropik. Lintasan neutron dalam PGNAA berasal dari teras reaktor yang menembus moderator kemudian terkolimasi dalam kolimator PGNAA. Intensitas neutron yang keluar dari medium moderator $\left(\mathrm{I}_{\mathrm{m}}\right)$ dapat ditentukan dengan pendekatan sebagai berikut: di mana lo adalah intensitas sumber $\left(\mathrm{n} / \mathrm{cm}^{2}\right.$ s), A adalah luas penampang efektif moderator $\left(\mathrm{cm}^{2}\right), \mathrm{L}_{m}$ panjang moderator, dan $\Sigma_{a}$, adalah tampang lintang absorpsi makroskopik. A ditetapkan sesuai dengan konstanta kolimator (D/L) dan panjang kolimator $\left(L_{k}\right)$ yang digunakan yaitu:

$$
A=\pi\left[\frac{\frac{D}{L}\left(L_{m}+L_{k}\right)}{2}\right]^{2}
$$

Intensitas neutron yang keluar dari moderator diterima oleh kolimator untuk disaring menjadi berkas neutron sejajar. Selama melintas kolimator, berkas neutron mempunyai kebolehjadian berinteraksi dengan atom udara pengisi kolimator. Besarnya intensitas neutron yang keluar dari ujung kolimator (I') dapat ditentukan dengan pendekatan formulasi attenuasi neutron sebagai berikut:

$$
I^{\prime}=I_{m} \exp \left(\Sigma_{a} L_{k}\right)
$$

Sedangkan arus neutron yang terukur di dalam sistem PGNAA (In) pada luas permukaan $(A)$ dihitung dengan persamaan

$$
I_{n}=A I
$$

Kolimator neutron digunakan untuk penyaring berkas neutron sejajar yang dapat melewatinya. Batas sejajar berkas 
ditentukan oleh nilai D/L kolimator. D adalah diameter dan $\mathrm{L}$ adalah panjang kolimator, dengan nilai $\mathrm{D} / \mathrm{L}$ yang makin kecil akan menghasilkan berkas neutron yang makin mendekati sejajar. Untuk kebutuhan kolimator yang direncanakan dalam PGNAA dengan sumber neutron teras reaktor Kartini ditetapkan nilai $\mathrm{D} / \mathrm{L}$ sebesar 0,015 , dengan mengacu nilai $D / L$ tersebut dapat ditetapkan diameter kolimator apabila telah ditetapkan panjang kolimator. Diameter kolimator berkaitan dengan luas kolimator dan arus neutron yang direncanakan.

\section{TATA KERJA}

Sistem PGNAA ini dirancang menggunakan sumber neutron dari teras reaktor Kartini yang tersalur melalui saluran berkas (beamport) untuk radiasi sampel. Spektrum energi neutron hasil pembelahan di dalam teras reaktor tersebut adalah majemuk seperti terlihat dari hasil perhitungan MCNP yang dilakukan oleh Tegas S (11) dan ditampilkan pada Tabel 1 menunjukkan bahwa spektrum energi neutron pada beamport terdistribusi merata pada kelompok energi termal, epitermal dan cepat. Sedangkan sistem PGNAA membutuhkan sumber neutron termal dengan jangkau energi (12 meV - 100 $\mathrm{meV}$ ), sehingga neutron dari sumber teras reaktor Kartini memerlukan media untuk proses moderasi neutron sedemikian rupa sehingga jangkau energi neutron dapat turun dan memenuhi kriteria sistem PGNAA.

Dirancang sistem PGNAA dengan susunan komponen utama meliputi : moderator, kolimator 1 dan kolimator 2 , beam shutter, perisai neutron dan gamma, ruang sampel, dan beam stopper. Diagram skematik rancangan sistem PGNAA dengan sumber neutron beamport reaktor Kartini dilukiskan pada Gambar 2 di mana sistem PGNAA terbagi dalam 3 zona yaitu zona teras, zona beamport dan zona instrumentasi.

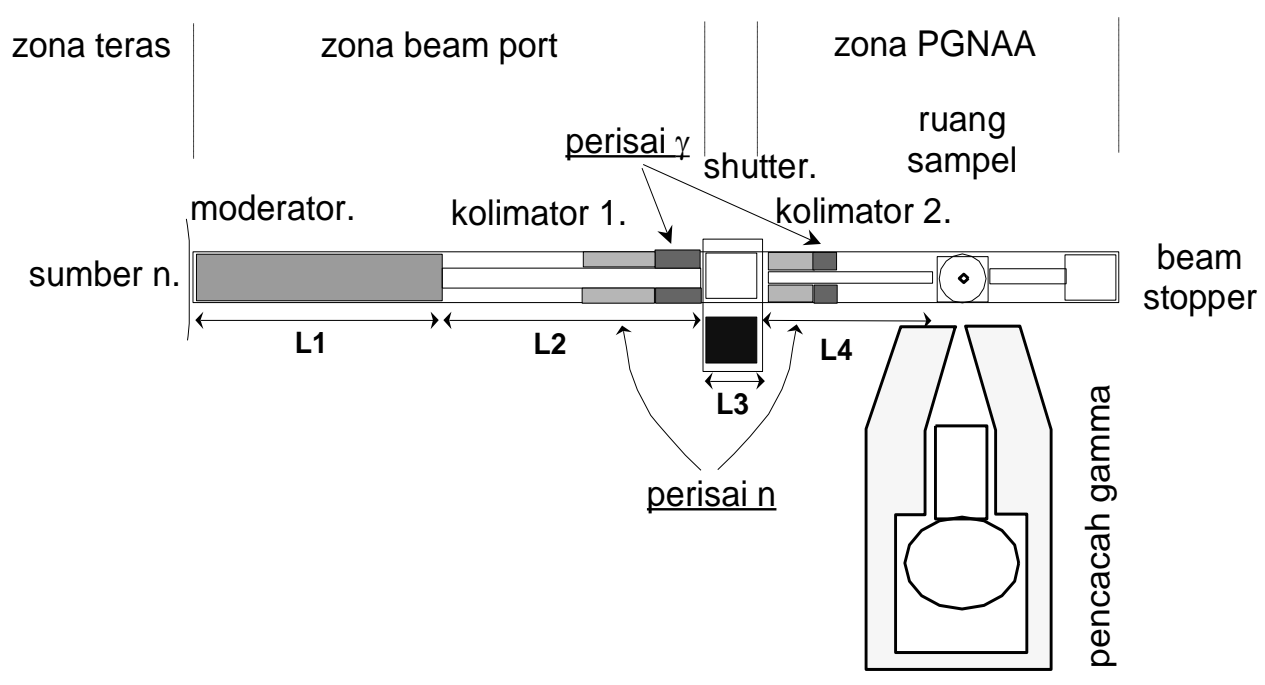

Gambar 2. Diagram konstruksi PGNAA dengan sumber neutron dari beamport reaktor Kartini 
Pada zona teras, berkas neutron mempunyai energi majemuk. Selanjutnya pada zona beamport berkas dibuat mengalami proses moderasi menjadi neutron termal, kemudian dilewatkan kolimasi 1 untuk mendapatkan berkas neutron yang sejajar dalam spektrum energi neutron yang mayoritas telah menjadi termal. Shutter digunakan sebagai gerbang untuk menutup atau membuka berkas neutron termal dari teras reaktor Kartini guna pemanfaatan dalam PGNAA. Dalam zona PGNAA berkas neutron dilewatkan kolimasi 2 untuk mengarahkan neutron sejajar menuju ruang pencacahan PGNAA. Berkas neutron yang lolos dari ruang pencacahan diteruskan kedalam beam stopper untuk diserap sehingga tidak menyebabkan noise dalam sistem pencacahan.

Konstruksi dan ukuran salah satu beamport reaktor Kartini yang akan digunakan untuk fasilitas PGNAA ini dilukiskan pada Gambar 3. Pada reaktor Kartini tersedia 4 beamport terdiri dari sebuah beamport tangensial dan dua buah beamport radial tidak tembus dan sebuah beamport radial tembus. Beamport radial tembus menghasilkan neutron yang langsung dari teras tanpa melalui medium grafit sedangkan beamport radial tidak tembus menghasilkan neutron dari teras dengan melalui medium grafit reflektor.

Dilakukan analisis pemilihan beamport untuk sumber neutron PGNAA dan pada rancangan ini dipilih beamport radial tembus karena memiliki fluks neutron yang paling tinggi, dibanding beamport singgung seperti hasil simulasi yang dilakukan oleh Tegas S (1116). Dilakukan perhitungan dan analisis terhadap flux neutron pada permukaan dalam beamport radial tembus dengan MCNP dengan hasil sesuai penelitian Tegas $S$ dan Syarip (11) seperti ditunjukkan pada Tabel 1.

Tabel 1. Fluks neutron pada permukaan bagian dalam beamport radial tembus (11).

\begin{tabular}{cc}
\hline Jangkau energi & Fluks $\mathrm{n}\left(\mathrm{n} / \mathrm{cm}^{2} \mathrm{~s}\right)$ \\
\hline $0-0.5 \mathrm{eV}$ & $6,0.10^{11}$ \\
$0.5 \mathrm{eV}-1 \mathrm{MeV}$ & $5,0.10^{11}$ \\
$>1 \mathrm{MeV}$ & $4,0.10^{11}$ \\
total & $1,5.10^{12}$ \\
\hline
\end{tabular}

Terlihat dari Tabel 1 bahwa distribusi energi neutron sebagian berada pada zona termal, epitermal dan cepat dengan distribusi rata. Dibutuhkan moderator untuk menghasilkan neutron termal yang dominan untuk kebutuhan PGNAA.

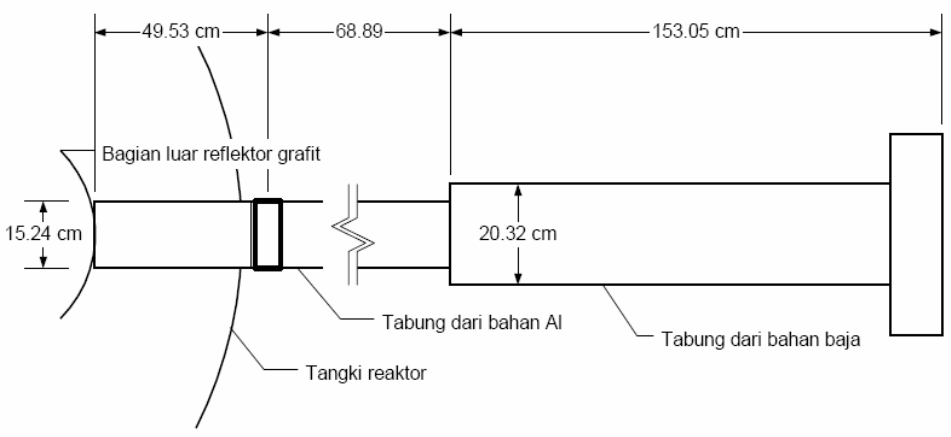

Gambar 3. Beamport radial tembus reaktor Kartini (11) 


\section{HASIL DAN PEMBAHASAN}

Konstruksi PGNAA menggunakan sumber neutron dari beamport reaktor Kartini dibuat mengikuti ketentuan dalam Gambar 2., dengan nilai L1, L2 dan L3 sedemikian rupa sehingga sesuai dengan konstruksi beamport reaktor Kartini. Dari hasil penyesuaiannya diperoleh ukuran geometri subkomponen penyusun PGNAA seperti pada Tabel 2. Sebagai pengendali arus neutron dalam ruang pencacahan PGNAA digunakan shutter untuk memutuskan berkas neutron dari sumber dan beam stopper untuk menyerap berkas neutron yang tidak terpakai dalam ruang pencacahan PGNAA. Komponen moderator dan kolimator neutron dipasang pada kolom beamport sedangkan sebagai shutter neutron digunakan jendela penutup beamport. Sebagian penggal kolimator yang menyambungkan berkas neutron ke ruang aktivasi PGNAA dipasang di muka jendela shutter neutron. Ruang aktivasi dan beam stopper neutron dipasang sesudah kolimator. Untuk mengurangi noise pencacahan, dipasang perisai neutron dan perisai gamma pada sekitar kolimator.

Bahan moderator yang dipertimbangkan pada rancangan fasilitas PGNAA ini adalah: air berat, air, grafit, berilium, polyethylen dan parafin. Dilakukan perbandingan parameter neutronik dari masingmasing material tersebut dalam menjaga neutron tidak tertangkap dalam medium selama proses moderasi dari energi $1 \mathrm{MeV}$ sampai menjadi neutron termal. Pada rancangan model PGNAA ini, moderator dibuat sebagai medium lintasan neutron sumber menuju ke kolimator seperti pada Gambar 2, dimana dalam menembus medium diperhitungkan terjadi proses moderasi yang akan menurunkan energi kinetik neutron yang berhasil melintasi medium. Dengan menggunakan formulasi parameter neutronik yang dideskripsikan di atas yaitu persamaan (1) $\mathrm{s} / \mathrm{d} \quad$ (10) selanjutnya dihitung dan dibandingkan nilai parameter neutronik dalam menghasilkan neutron termal. Hasil perhitungan selengkapnya ditampilkan pada Tabel 3 dan Tabel 4.

Untuk mendapatkan moderator yang baik digunakan kriteria komparasi parameter neutronik sbb: tampang lintang absorbsi relatif kecil, tampang lintang hamburan relatif besar, penurunan energi logaritmik per tumbukan besar, jumlah tumbukan neutron menuju termal kecil, jarak jelajah rerata relatif kecil, efisiensi moderasi besar, daya moderasi besar, dan kebolehjadian bebas tangkapan atom moderator relatif besar

Berdasar hasil pembandingan parameter neutronik diatas diperoleh air berat, grafit dan berilium sebagai bahan moderator yang kompetitif karena bahan lainnya gagal dalam memberikan kebolehjadian bebas serapan neutron relatif tinggi selama melintasi medium moderator yang ditetapkan $90 \mathrm{~cm}$. Dari ketiga bahan tersebut grafit dapat dijadikan pilihan bahan moderator karena mudah didapat dibanding kan bahan moderator lainnya, hal ini sesuai dengan hasil penelitian Hashem MiriHakimabad (10). Grafit memberikan keuntungan sedikit menyerap neutron dan 
memberikan kebolehjadian menghamburkan neutron lebih besar dari bahan lainnya, sehingga jika menjadi moderator akan menghasilkan kebolehjadian neutron termal yang lebih banyak. Perancangan kolimator ditetapkan berdasar perbandingan nilai $\mathrm{D} / \mathrm{L}$ yang merepresentasikan kemampuan menyaring berkas jejak neutron yang bersifat koheren/sejajar. Nilai D/L makin kecil akan menghasilkan kualitas berkas yang makin koheren akan tetapi berakibat intensitas berkas yang makin kecil.
Ditetapkan dalam desain konstanta $\mathrm{D} / \mathrm{L}=$ 0,015 akan menghasilkan berkas neutron koheren dengan intensitas memenuhi syarat kebutuhan analisis dalam PGNAA. Udara dalam kolimator dapat mengurangi kualitas kinerja kolimator karena terjadi proses hamburan oleh molekul udara dalam kolimator. Untuk menghindari ini dilakukan analisis perubahan tekanan udara terhadap karakteristik neutroniknya. Hasil perhitungan ditampilkan pada Tabel 5 dan Tabel 6 .

Tabel 2. Ukuran Geometri komponen pengendali neutron PGNAA

\begin{tabular}{ccc}
\hline Sub komponen & Geometri & Ukuran \\
\hline Moderator (L1)) & Silinder & L1: $90 \mathrm{~cm}, \varnothing: 15 \mathrm{~cm}$ \\
Kolimator I (L2) & Pipa & L2: $113 \mathrm{~cm}, \varnothing: 5 \mathrm{~cm}$ \\
Kolimator II (L4) & Pipa & L4: $60 \mathrm{~cm}, \varnothing: 3 \mathrm{~cm}$
\end{tabular}

Tabel 3. Hasil perhitungan parameter neutronik material bahan moderator

\begin{tabular}{cccccccc}
\hline Moderator & $\rho(\mathrm{g} / \mathrm{cc})$ & $\Sigma_{\mathrm{a}}\left(\mathrm{cm}^{-1}\right)$ & $\Sigma_{\mathrm{s}}\left(\mathrm{cm}^{-1}\right)$ & $\Sigma_{\mathrm{t}}\left(\mathrm{cm}^{-1}\right)$ & $\xi$ & $\mathrm{N}$ & $\lambda(\mathrm{cm})$ \\
\hline Air berat & 1,1 & 0,000034 & 0,64 & 0,64 & 0,74 & 23 & 1,56 \\
Air & 1,0 & 0,02220 & 5,59 & 5,61 & 0,98 & 18 & 0,18 \\
Grafit & $\mathbf{1 , 6}$ & $\mathbf{0 , 0 0 0 2 7}$ & $\mathbf{0 , 3 8}$ & $\mathbf{0 , 3 9}$ & $\mathbf{0 , 2 8}$ & $\mathbf{6 2}$ & $\mathbf{2 , 6 0}$ \\
Berilium & 1,85 & 0,00120 & 0,87 & 0,87 & 0,36 & 49 & 1,15 \\
Polyethylen & 0,94 & 0,03150 & 7,89 & 7,92 & 0,98 & 18 & 0,13 \\
Parafin & 0,8 & 0,04660 & 11,60 & 11,60 & 0,99 & 18 & 0,09 \\
\hline
\end{tabular}

Keterangan: $\Sigma_{\mathrm{a}}, \Sigma_{\mathrm{s}}$ dan $\Sigma_{\mathrm{t}}$ masing-masing adalah tampang makroskopis absorbsi, hamburan dan total. $\xi$ adalah penurunan energi logaritmik/ tumbukan, $\mathrm{N}$ adalah jumlah tumbukan neutron dari energi cepat sampai ke termal, dan $\lambda$ adalah jarak jelajah rerata.

Tabel 4. Hasil perhitungan parameter neutronik material bahan moderator

\begin{tabular}{ccccc}
\hline Moderator & $\begin{array}{c}\text { Efisiensi } \\
\text { moderasi }\end{array}$ & $\begin{array}{c}\text { Daya } \\
\text { moderasi }\end{array}$ & $\begin{array}{c}\text { Panjang } \\
\text { moderator }(\mathrm{cm})\end{array}$ & $\begin{array}{c}\text { Kebolehjadian neutron bebas } \\
\text { tangkapan atom moderator }\end{array}$ \\
\hline Air berat & 14000. & 0,48 & 90 & 0,99 \\
Air & 2470. & 5,48 & 90 & 0,13 \\
Grafit & 401. & $\mathbf{0 , 1 1}$ & 90 & $\mathbf{0 , 9 8}$ \\
Berilium & 265 & 0,31 & 90 & 0,90 \\
Polyethylen & 246 & 7,75 & 90 & 0,06 \\
Parafin & 246 & 11,5 & 90 & 0,01 \\
\hline
\end{tabular}


Tabel 5. Hasil perhitungan tampang lintang makroskopis fungsi tekanan udara

\begin{tabular}{|c|c|c|c|c|}
\hline \multirow{2}{*}{$\begin{array}{l}\text { Komposisi udara } \\
\text { standard } \mathrm{P}=1 \\
\text { atm, } \mathrm{T}=27^{0} \mathrm{C}\end{array}$} & \multirow{2}{*}{$\begin{array}{l}\text { Massa jenis } \\
\text { udara }(\mathrm{gr} / \mathrm{cc})\end{array}$} & \multicolumn{3}{|c|}{$\begin{array}{l}\text { Tampang lintang makroskopis } \\
\qquad\left(\mathrm{cm}^{-1}\right)\end{array}$} \\
\hline & & absorbsi & hamburan & total \\
\hline \multicolumn{5}{|l|}{ Argon: $0,93 \%$} \\
\hline N2: $78,08 \%$ & $1,17.10^{-3}$ & $2,90.10^{-4}$ & $2,28.10^{-3}$ & $2,5.10^{-3}$ \\
\hline O2: $20,95 \%$ & & & & \\
\hline
\end{tabular}

Tabel 6. Hasil perhitungan kebolehjadian bebas tumbukan neutron dengan molekul udara dalam kolomator

\begin{tabular}{cccc}
\hline $\begin{array}{c}\text { Komposisi } \\
\text { udara }\end{array}$ & $\begin{array}{c}\text { Panjang } \\
\text { kolimator }\end{array}$ & $\begin{array}{c}\text { Tekanan udara } \\
\text { dlm kolimator }\end{array}$ & $\begin{array}{c}\text { Kebolehjadian neutron bebas } \\
\text { tumbukan dengan atom udara }\end{array}$ \\
\hline Argon: $0,93 \%$ & $173 \mathrm{~cm}$ & $0,1 \mathrm{~atm}$ & 0,64 \\
N2: $78,08 \%$ & 1 torr & 0,96 \\
O2: $20,95 \%$ & & 0,999 \\
\hline
\end{tabular}

Tabel 7. Data hasil perhitungan karakteristik sumber neutron pada beamport radial tembus untuk PGNAA

\begin{tabular}{|c|c|c|}
\hline Paremeter & Nilai/ spesifikasi & Keterangan \\
\hline Sumber neutron & $\begin{array}{c}\text { Intensitas: } 1,5.10^{12} \\
\mathrm{n} / \mathrm{cm}^{2} \mathrm{~s}\end{array}$ & $\begin{array}{c}\text { Spesifikasi: neutron cepat. Berkas neutron menyebar, } \\
\text { isotrop. Geometri sumber: luasan }\end{array}$ \\
\hline Moderator & $\begin{array}{l}\text { Diameter: } 15 \mathrm{~cm} \\
\text { Panjang: } 90 \mathrm{~cm}\end{array}$ & Bahan: Grafit \\
\hline $\begin{array}{l}\text { Intensitas neutron } \\
\text { termoderasi }\end{array}$ & $1,76.10^{8} \mathrm{n} / \mathrm{cm}^{2} \mathrm{~s}$ & Neutron termal, berkas neutron menyebar, isotrop \\
\hline Kolimator & $\begin{array}{l}D / L=0,015 \\
L=173 \mathrm{~cm}\end{array}$ & Tekanan udara $=1$ torr \\
\hline $\begin{array}{l}\text { Intensitas neutron } \\
\text { terkolimasi }\end{array}$ & $1,76.10^{8} \mathrm{n} / \mathrm{cm}^{2} \mathrm{~s}$ & Neutron termal, berkas neutron sejajar \\
\hline Luas penampang & $5,29 \mathrm{~cm}^{2}$ & $\varnothing=2,6 \mathrm{~cm}$ \\
\hline Arus berkas & $9,29.10^{8} \mathrm{n} / \mathrm{s}$ & Spesifikasi: neutron termal. Berkas sejajar \\
\hline
\end{tabular}

Tampak bahwa tekanan udara dalam kolimator mempengaruhi lintasan neutron. Untuk menghindari gangguan tersebut, kolimator PGNAA direncanakan terbuat dari bahan pipa aluminium yang rapat pada kedua ujungnya dan kedap udara. Permukaan fisik pipa bagian dalam dibuat halus dan dihampakan hingga tekanan udara mendekati 1 torr untuk membuat attenuasi neutron udara menjadi minimal. Ketetapan kolimasi $\mathrm{D} / \mathrm{L}=0,015$ dan dameter berkas neutron dari kolimator ditetapkan sebesar 2,6 cm. Arus neutron diperoleh sebagai hasil kali antara intensitas berkas dengan luas permukaan kolimator. Intensitas berkas diperoleh dari hasil perhitungan untuk bahan moderator grafit dan tetapan kolimator $\mathrm{D} / \mathrm{L}=0,015$ 
ditampilkan pada Tabel 7. Berdasar hasil perhitungan perancangan PGNAA dengan sumber neutron dari beamport radial tembus reaktor Kartini dapat menghasilkan intensitas pada permukaan sample sebesar $1,79.10^{8} \mathrm{n} / \mathrm{cm}^{2} \mathrm{~s}$ dan arus berkas neutron $9,48.10^{8} \mathrm{n} / \mathrm{s}$. Diharapkan berkas neutron tersebut mayoritas adalah neutron termal.

Berdasarkan data IAEA (1) intensitas (fluks) neutron dari beberapa fasilitas PGNAA di beberapa negara seperti India (BARC), Korea (KAERI), Vietnam (Nuclear Research Institute, Dalat), Hongaria (Budapest Research Reactor), menunjukkan bahwa fluks neutron termal yang layak untuk PGNAA adalah berkisar pada orde $10^{6} \mathrm{~s} / \mathrm{d}$ $10^{8} \mathrm{n} / \mathrm{cm}^{2} \mathrm{~s}$. Hasil serupa untuk disain dan konstruksi fasilitas PGNAA di reaktor InHospital Neutron Irradiator (IHNI) di Beijing dengan fluks neutron termal $3.10^{6} \mathrm{n} / \mathrm{cm}^{2} \mathrm{~s}$ pada daya penuh $30 \mathrm{~kW}$ Zizhu Zhang et.al. (17). Sedangkan pada fasilitas PGNAA di reaktor TRIGA Oregon State University memberikan fluks neutron termal pada permukaan sample $2,8.10^{7} \mathrm{n} / \mathrm{cm}^{2} \mathrm{~s}$ seperti yang dilaporkan oleh Robinson J.A., et.al. (18). Bahkan fasilitas PGNAA di reaktor RA3 Argentina fluks neutron bisa mencapai orde $10^{9} \mathrm{n} / \mathrm{cm}^{2} \mathrm{~s}$ seperti yang ditulis oleh Manuel L. (13). Demikian pula sistem PGNAA yang telah diaplikasikan di industri batubara memiliki nilai fluks neutron berkisar seperti pada nilai fluks di atas seperti yang dilaporkan oleh Qian Zhu (2) dan Henry Kurth (3). Untuk menghindari radiasi gamma sekunder yang berasal dari interaksi neutron dengan material perisai maka perisai gamma ditambahkan pada bagian luar perisai neutron yang terpasang. Perisai gamma direncana dari bahan timah yang dikonstruksi sesuai dengan geometri ruang yang membutuhkannya. Nilai tampang lintang serapan neutron yang besar pada perisai neutron dapat diperoleh dengan membuat komposit dari bahan penyerap neutron dan moderator. Sebagai bahan perisai neutron pada PGNAA dipertimbangkan penggunaan bahan yang mudah didapat yaitu: campuran parafin $\left(\mathrm{C}_{n^{-}}\right.$ $\left.\mathrm{H}_{2 \mathrm{n}+2}\right)$ dengan borax $\left(\mathrm{Na}_{2} \mathrm{~B}_{4} \mathrm{O}_{7} \cdot 10 \mathrm{H}_{2} \mathrm{O}\right)$, bahan ini terbukti cukup baik digunakan pada sistem NAA invivo sesuai hasil penelitian Rezaei Moghaddam (14).

Beam stopper, perisai neutron dan shutter pada PGNAA berfungsi untuk menutup berkas neutron yang tidak dikehendaki. Bahan yang digunakan untuk kebutuhan ini adalah komposit yang banyak mengandung penyerap neutron sehingga dapat diperoleh ukuran tebal yang dapat diminimumkan. Shutter digunakan untuk menutup berkas pada kolimator apabila tidak digunakan. Perisai neutron digunakan untuk menutup berkas neutron yang keluar dari, sela antara dinding kolimator dengan kolom beamport dan beam stopper digunakan untuk menyerap berkas neutron yang tidak termanfaatkan dalam ruang iradiasi dalam sistem PGNAA. Posisi komponen beam stopper, perisai neutron dan shutter dalam sistem PGNAA dapat dilihat pada Gambar 2. Berdasar hasil perhitungan tampang lintang makroskopis kompositnya diperoleh data sifat attenuasi neutron yang makin tinggi konsentrasi borax dalam komposit parafin-borax menghasilkan sifat attenuasi neutron yang makin baik tetapi menghasilkan sifat komposit yang 
makin rapuh. Oleh karena itu ditetapkan komposit perisai parafin-borax menggunakan konsentrasi borax $25 \%$ berat dari berat kompositnya. Pada perisai komposit parafin $25 \%$ berat borax tebal 30 $\mathrm{cm}$ terhitung menghasilkan attenuasi neutron atau kebolehjadian meloloskan neutron tanpa interaksi tumbukan sebesar $8,7.10^{-88}$, nilai ini sangat kecil dibandingkan dengan nilai 1 yang mengindikasikan medium tanpa perisai. Bahan perisai lainnya yang dibutuhkan dalam komponen PGNAA adalah plat LiF sebagai penyekat ruang pencacahan sampel PGNAA yang mempunyai sifat dapat menangkap neutron tidak menghasilkan radiasi gamma dan timah hitam $(\mathrm{Pb})$ sebagai bahan perisai gamma perangkat pencacahan yang digunakan dalam sistem PGNAA.

Hasil perhitungan komposisi bahan dan geometri komponen untuk konstruksi
PGNAA dengan sumber neutron reaktor Kartini ditampilkan pada Tabel 8. Untuk sistem pencacahan telah tersedia sistem spektrometri gama dengan detektor neutron HPGe yang telah digunakan untuk uji coba sistem PGNAA berbasis sumber neutron PuBe seperti yang dilaporkan Syarip (15). Sistem PGNAA berbasis sumber neutron dari reaktor ini diharapkan dapat dijadikan sarana pembanding hasil analisis unsur unsur dengan sistem PGNAA berbasis sumber neutron isotopik maupun generator neutron yang telah banyak diaplikasikan untuk analisis limbah industri, medis, sampel lingkungan maupun bahan peledak seperti beberapa laporan peneltian a.I. Muhammad Saleem (5), D. L. Chichester (8), dan Dariush Rezai (9)

Tabel 8. Spesifikasi hasil analisi awal rancangan konstruksi komponen PGNAA dengan sumber neutron dari beamport reaktor Kartini (lihat Gambar 2)

\begin{tabular}{|c|c|c|c|}
\hline Komponen & Geometri & Ukuran & Bahan \\
\hline Perisai neutron (1) & Silinder berlubang & $\begin{array}{c}\mathrm{L}: 30 \mathrm{~cm}, \varnothing_{\text {luar: }}: 20 \mathrm{~cm} \\
\varnothing_{\text {dalam }}: 5,5 \mathrm{~cm}\end{array}$ & $\begin{array}{c}\text { Komposit parafin } 25 \% \\
\text { berat borax }\end{array}$ \\
\hline Perisai neutron (2) & $\begin{array}{l}\text { Bujur sangkar berlubang } \\
\text { silinder }\end{array}$ & $\begin{array}{c}\mathrm{L}: 20 \mathrm{~cm}, \varnothing_{\text {lobang }}: 3 \mathrm{~cm} \text {, rusuk a: } 20 \\
\mathrm{~cm}\end{array}$ & $\begin{array}{c}\text { Komposit parafin } 25 \% \\
\text { berat borax }\end{array}$ \\
\hline Perisai gamma (1) & Silinder berlubang & $\begin{array}{c}\mathrm{L}: 20 \mathrm{~cm}, \varnothing_{\text {luar: }}: 20 \mathrm{~cm}, \\
\varnothing_{\text {dalam }}: 5,5 \mathrm{~cm}\end{array}$ & Timah hitam $(\mathrm{Pb})$ \\
\hline Perisai gamma (2) & $\begin{array}{l}\text { Bujur sangkar berlubang } \\
\text { silinder }\end{array}$ & $\begin{array}{l}\mathrm{L}: 10 \mathrm{~cm}, \varnothing_{\text {lobang }}: 3 \mathrm{~cm} \text {, rusuk a: } \\
20 \mathrm{~cm}:\end{array}$ & Timah hitam $(\mathrm{Pb})$ \\
\hline Shutter & Balok pejal & L3: $8 \mathrm{~cm}, \mathrm{P}: 22 \mathrm{~cm}, \mathrm{~L}: 22 \mathrm{~cm}$ & $\begin{array}{c}\text { Komposit parafin } 25 \% \\
\text { berat borax }\end{array}$ \\
\hline \multirow[t]{2}{*}{ Beam stopper } & Balok pejal berongga silinder & $\begin{array}{c}\text { Balok: } 30 \mathrm{~cm} \times 30 \mathrm{~cm} \times 30 \mathrm{~cm} \\
\text { Rongga } \varnothing: 5 \mathrm{~cm}, \mathrm{~L}: 8 \mathrm{~cm}\end{array}$ & $\begin{array}{c}\text { Komposit parafin } 25 \% \\
\text { berat borax }\end{array}$ \\
\hline & Pelat tebal $2 \mathrm{~cm}$ & $30 \mathrm{~cm} \times 30 \mathrm{~cm}$ & Timah hitam $(\mathrm{Pb})$ \\
\hline $\begin{array}{l}\text { Perisai pencacah } \\
\text { gamma PGNAA }\end{array}$ & $\begin{array}{l}\text { Susunan lead brick } \\
\text { membentuk ruang }\end{array}$ & $\begin{array}{c}\text { Geometri dan volume bergantung } \\
\text { pada ukuran detektor yang } \\
\text { digunakan }\end{array}$ & Timah hitam (Pb) \\
\hline $\begin{array}{l}\text { Ruang aktivasi } \\
\text { PGNAA }\end{array}$ & Pelat tebal $2 \mathrm{~cm}$ & $15 \times 15 \times 15 \mathrm{~cm}$ & LiF \\
\hline
\end{tabular}




\section{KESIMPULAN}

Menurut hasil analisis awal rancangan sistem PGNAA untuk sampel lingkungan dengan sumber neutron dari beamport reaktor Kartini cukup layak, dan perlu dilakukan analisis ulang yang lebih rinci sebelum direalisasikan. Sebagai moderator neutron digunakan bahan grafit dengan panjang $90 \mathrm{~cm}$. Kolimator neutron berbentuk pipa aluminium panjang $173 \mathrm{~cm}$ dengan tetapan $\mathrm{D} / \mathrm{L}=0,015$ dan dihampakan dengan tekanan $\leq 1$ torr. Berkas neutron dari beamport yang tidak melalui kolimator dihentikan menggunakan perisai neutron disekitar kolimator yang terbuat dari bahan komposit parafin $25 \%$ berat borax. Sedangkan radiasi gamma dihentikan menggunakan perisai timah hitam. Berdasar hasil perhitungan disimpulkan bahwa dari intensitas neutron total beamport radial bagian dalam yang menempel pada teras reaktor Kartini sebesar $1,5.10^{12} \mathrm{n} / \mathrm{cm}^{2} \mathrm{~s}$ dapat menghasilkan berkas neutron dengan arus sebesar $9,29.10^{8} \mathrm{n} / \mathrm{s}$ dan intensitas neutron termal $1,76.10^{8} \mathrm{n} / \mathrm{cm}^{2} \mathrm{~s}$ di ruang aktivasi PGNAA. Intensitas neutron termal tersebut sudah memenuhi persyaratan untuk suatu sistem PGNAA yaitu berada pada orde $10^{6} \mathrm{~s} / \mathrm{d} 10^{8} \mathrm{n} / \mathrm{cm}^{2} \mathrm{~s}$.

\section{DAFTAR PUSTAKA}

1. INTERNATIONAL ATOMIC ENERGY AGENCY (IAEA), Database of prompt gamma rays from slow neutron capture for elemental analysis, Vienna, IAEA, STI/PUB/1263, 2007.

2. Qian Zhu, Coal sampling and analysis standards, IEA Clean Coal Centre, Park
House 14 Northfields London SW18 1DD, 2014. 93p.

3. Henry Kurth, Real time on-belt elemental analysis using PGNAA for mineral processing plant control, Scantech International Pty Ltd, Australia; 2014. Available from: http://web.cim.org/push_file.cfm

4. Darrel Leetham, PGNAA improves process and quality control in cement production, Thermo Fisher Scientific, June 2014. Available from: http://acceleratingscience.com

5. Muhammad Saleem, Determination of cadmium concentration in water samples using prompt gamma neutron activation technique, PHYS 505 Graduate Lab, ID \# G200902830, 2010.

6. Massimo Rogante, et al., Feasibility study for a neutron-based investigation of polymer cement concretes, Universal Journal of Applied Science. 2013; 1(1): 11-17.

7. Naqvi AA, et al., Optimization of a prompt gamma setup for analysis of environmental samples, Journal of Radioanalytical and Nuclear Chemistry, April 2013; 2961: 215-221.

8. Chichester DL, Caffrey AJ, Twomey TR. Nondestructive identification of chemical warfare agents and explosives by neutron generator-driven PGNAA, SciTech Connect; 2007; Technical Meeting - Neutron Generators for Activation Analysis Purposes, Vienna, Austria.

9. Dariush Rezai, Mohammad Mohammadi. Prompt gamma neutron activation 
analysis of carbon bulk samples with an

Am-Be neutron source, Journal of

Theoretical Physics and Criptography, JPTC, November 2012; 1(1).

10.Hashem Miri-Hakimabad, et al.: An optimum landmine detection system using polyethylene moderator and ${ }^{241} \mathrm{Am}$ Be as a neutron source, Asian J. Exp. Sci., 2008; 22(1): 153-158.

11.Tegas Sutondo, Syarip, Karakteristik berkas pada beamport tembus dan singgung reaktor Kartini, Jurnal Iptek Nuklir Ganendra, Juli 2014; 17(2): 83-90.

12.Glasstone S, Sesonske A, Nuclear Reactor Engineering, Fourth Edition, Volume One, Springer, 1994.

13.Manuel L. at al.: Development of a prompt gamma neutron activation analysis facility for ${ }^{10} \mathrm{~B}$ concentration measurements at RA-3: Design Stage, Applied Radiation and Isotopes, December 2011; 69(12): 1928-1931.

14.Rezaei Moghaddam Y. et al.: Optimization of body composition analyzer facility considering operator dosimetry, J Biomed Phys Eng. 2012; 2(4).

15.Syarip, Eksperimen pembuatan sistem penganalisis unsur dengan metode gama serentak menggunakan sumber neutron Pu-Be. Jurnal Iptek Nuklir Ganendra, 2002; 5(1): 23-30.

16.Tegas Sutondo, Beam modeling for PGNAA experimental facility at Kartini reactor, J. Iptek Nuklir Ganendra, Juli 2015; 18(2): 107-113.

17.Zizhu Zhang, Yizheng Chong, Xinru Chen, Congjun Jin, Lijun Yang, Tong Liu, PGNAA system preliminary design and measurement of In-Hospital Neutron Irradiator for boron concentration measurement, Applied Radiation and Isotopes, December 2015; 106: 161-165.

18.Robinson J.A., Hartman M.R. and Reese S. R. (2010). Design, construction and characterization of a prompt gamma activation analysis facility at the Oregon State University TRIGA reactor. Journal of Radioanalytical and Nuclear Chemistry, 2010; 283(2): 359-369. 